\title{
Rainfall spatial organization and areal reduction factors in the metropolitan area of Barcelona (Spain)
}

\author{
Raul Rodríguez • Xavier Navarro • M. Carmen Casas • \\ Angel Redaño
}

Received: 4 July 2012 / Accepted: 2 December 2012

(C) Springer-Verlag Wien 2012

\begin{abstract}
The rainfall spatial organization in the metropolitan area of Barcelona (Spain) has been studied from records of an urban rain gauge network in the period 1994-2009. Using statistical and regional analysis techniques, correlation between data recorded by the different rain gauges has been calculated, and the effective number of independent stations $\left(n_{\text {eq }}\right)$ equivalent to the used network has been determined. It has been found out that for durations longer than $20 \mathrm{~min}$, the areal rainfall return period observed for a storm registered by the network approximately decreases by a factor of $1 / n_{\text {eq }}$ in relation to the current point rainfall intensity-duration-frequency relationships for the metropolitan area of Barcelona. Using objective analysis techniques, continuous precipitation fields have been generated on a regular grid with a spatial resolution of $300 \times 300 \mathrm{~m}$ for the storms registered by the rain gauges from 1994 to 2009, for durations from $10 \mathrm{~min}$ to $24 \mathrm{~h}$. The precipitation fields obtained have been useful to estimate the characteristic areal reduction factors in the metropolitan area of Barcelona. A direct relationship has been found between the areal reduction factor for all the area corresponding to the urban rainfall network of Barcelona and the effective number of $n_{\text {eq }}$ for every duration considered.
\end{abstract}

\section{Introduction}

The spatial and temporal distribution of rainfall intensity is highly variable even on a small scale, particularly in intense

R. Rodríguez $\cdot$ X. Navarro $\cdot$ M. C. Casas $(\bowtie)$

Department of Physics and Nuclear Engineering, EPSEVG, Universitat Politècnica de Catalunya, Víctor Balaguer 1, 08800 Vilanova i la Geltrú, Spain

e-mail: m.carmen.casas@upc.edu

\section{A. Redaño}

Department of Astronomy and Meteorology,

Universitat de Barcelona, Av. Diagonal, 647,

08028 Barcelona, Spain rain events. The knowledge of the main features of these distributions is of great importance from the standpoint of the weather and in many applications (Niemczynowicz and Bengtsson 1996; Midkkelsen et al. 2005). For instance, besides the maximum rainfall intensities that can be registered, in urban hydrology, the spatial attenuation of these intensities with distance is required to determine the proper sizing of sewer networks in cities (Shah et al. 1996). Currently, this information can only be accurately and reliably obtained from data provided by dense networks of intensity rain gauges. Due to the difficulty of installing such networks in a city and the high cost of maintenance, there are few studies that address these issues, and few long-time series of such data are available. The metropolitan area of Barcelona has an urban network of 23 tipping bucket rain gauges supported by the company Clavegueram de Barcelona, S. A. (CLABSA), in operation since 1994. Although the CLABSA records are not long enough to climatologically characterize the regime of rainfall intensities in the area, network density has made possible to analyze in depth the rainfall spatial organization in the metropolitan area of Barcelona.

The correlation between intensity data registered by the different rain gauges of the network has been calculated, and the spatial distribution of rainfall intensity in a storm has been analyzed. The information gained due to the multiplicity of stations depends on the level of independency between observations and varies from no gain to the greatest possible, obtained when there is no correlation between the observations registered in different pluviometric stations. The correlation structure between different parts of the network has been analyzed using the principal component factorial analysis and the station-year method (NRC 1988), and the effective number or $n_{\text {eq }}$ of independent stations equivalent to the network employed has been determined. The purpose of this determination is to correctly estimate the recurrence of intense rainfall events in the whole region since this recurrence is currently estimated using the intensity-duration-frequency 
(IDF) curves calculated from rainfall data recorded by a single instrument.

Another interesting feature related to the rainfall spatial organization is the areal reduction factor (ARF), a correction factor to transform point rainfall depths to an equivalent rainfall depth over an area (Svensson and Jones 2010). A "storm-centered" approach (Omolayo 1993) has been applied to empirically estimate the ARFs for the metropolitan area of Barcelona. Rainfall data corresponding to storms registered by the network from 1994 to 2009, for durations from $10 \mathrm{~min}$ to $24 \mathrm{~h}$, have been employed. In order to calculate the areal rainfall depths, objective analysis techniques have been applied to generate precipitation fields on a regular grid with high spatial resolution $(300 \times 300 \mathrm{~m})$ over the urban area of Barcelona. The relationship between the ARF corresponding to an area and the recurrence of rainfall events registered in this area (Vaes 2007) has been investigated.

\section{Study of the spatial correlation among the network pluviometers. Obtention of the effective number of independent stations $\boldsymbol{n}_{\text {eq }}$ equivalent to the network}

The urban area of Barcelona (100 $\mathrm{km}^{2}$ approximately) has a dense microscale rain gauge network constituted by 23 high-resolution tipping bucket gauges (Table 1) supported by CLABSA, a company that controls the sewer systems of the city (Lorente and Redaño 1990; Casas et al. 2010). The pluviometers are made by the company Geónica S. A., with a collector funnel of $400 \mathrm{~cm}^{2}$ of surface and a resolution of $0.1 \mathrm{~mm}$. The integration time is $1 \mathrm{~min}$, and the maximum intensities calculated for durations shorter than $1 \mathrm{~h}$ could have been affected by an error of a $10 \%$, whereas for durations longer than $2 \mathrm{~h}$, the error determining the intensity is generally smaller than a $5 \%$ (Lanza et al. 2006). The continuous records of 22 of the pluviometers are available from 1996 to 2009. Five of these pluviometers started working in 1994, and there is a 23rd gauge operating from 2000. In terms of rainfall, the urban area can be considered a homogeneous region according to the Hosking and Wallis's homogeneity test made (Hosking and Wallis 1997).

The correlation among the rainfall intensity data registered by the urban network has been first studied using the principal component factorial analysis, taking into consideration the precipitation amounts registered by the 23 stations in 15 years (1994-2009) as the variables to be analyzed. The number of rainfall data analyzed varies from 3,300 for a duration of $10 \mathrm{~min}$ and 200 for a duration of $24 \mathrm{~h}$. Data have been selected in order to obtain serially independent samples. For instance, the selected rainfall data corresponding to $10 \mathrm{~min}$ are separated among them by gaps of at least $50 \mathrm{~min}$. Figure 1 shows the mean correlation coefficient between pluviometers calculated for durations
Table 1 Microscale rain gauges network supported by CLABSA in Barcelona

\begin{tabular}{|c|c|c|c|}
\hline \multirow{2}{*}{$\begin{array}{l}\text { Pluviometer } \\
\text { AGBE }\end{array}$} & \multirow{2}{*}{$\frac{\text { Altitude (m) }}{18}$} & \multicolumn{2}{|c|}{ Location (UTM) (m) } \\
\hline & & 432572 & 4590189 \\
\hline AGCO & 15 & 422530 & 4579549 \\
\hline AGTI & 450 & 426690 & 4586494 \\
\hline AGTR & 162 & 430034 & 4585878 \\
\hline AJNO & 8 & 431351 & 4581678 \\
\hline AJSA & 120 & 426648 & 4583627 \\
\hline AJUO & 86 & 429270 & 4584410 \\
\hline BARK & 9 & 428485 & 4578698 \\
\hline CANY & 148 & 430181 & 4588414 \\
\hline CATA & 7 & 433279 & 4585023 \\
\hline CLAB & 4 & 427987 & 4578247 \\
\hline COTX & 27 & 427879 & 4580946 \\
\hline DEIN & 37 & 428911 & 4582279 \\
\hline DEPU & 5 & 435184 & 4584975 \\
\hline ELIZ & 32 & 430373 & 4583077 \\
\hline FCCF & 3 & 427443 & 4576149 \\
\hline FISI & 67 & 426341 & 4582030 \\
\hline HEUR & 206 & 428357 & 4587775 \\
\hline MONT & 146 & 430431 & 4579649 \\
\hline NABI & 293 & 425042 & 4585529 \\
\hline NICA & 3 & 433035 & 4582822 \\
\hline ROLI & 14 & 434117 & 4587439 \\
\hline SAGR & 26 & 432334 & 4586332 \\
\hline
\end{tabular}

from $10 \mathrm{~min}$ to $24 \mathrm{~h}$, resulting higher than 0.7 for durations longer than $6 \mathrm{~h}$. For durations lower than $4 \mathrm{~h}$, the factorial analysis using the variance maximizing rotation resulted in two first principal components accounting for approximately the $70 \%$ of the total variance of the data, and the $76 \%$ if a third component is added. For durations longer than $4 \mathrm{~h}$, the two first principal components account for the $86 \%$ of the variance. The prevailing principal component for each network station has been determined considering which factor loading has resulted the largest in each case. Figure 2 is a spatial representation of this prevailing principal component in each station. This representation shows two or three zones, depending on the rain duration, probably showing slightly different pluviometric regimes over the urban area of Barcelona. The upper representation in Fig. 2, corresponding to $4 \mathrm{~h}$, shows a clear north-south distribution over the urban area (first principal component in the north and second in the south), as previously suggested by Lorente and Redaño (1990). For a shorter duration of 10 min (Fig. 2, down), a third principal component can be considered. In this case, the factorial analysis detects small differences in the north group, appearing a substructure with the highest stations of Barcelona (between 150 and $450 \mathrm{~m}$ of 


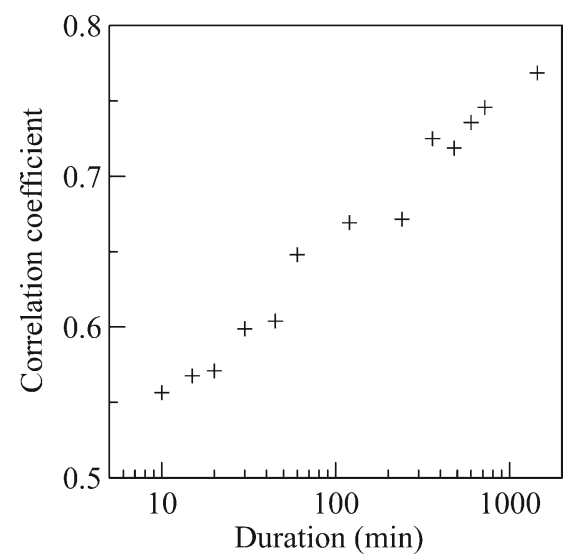

Fig. 1 Averaged correlation coefficient between the pluviometers of the urban network of Barcelona depending on the rainfall duration

altitude: NABI, AGTI, HEUR, and CANY on the Collserola range and AGTR on the Turo de la Rovira hill).

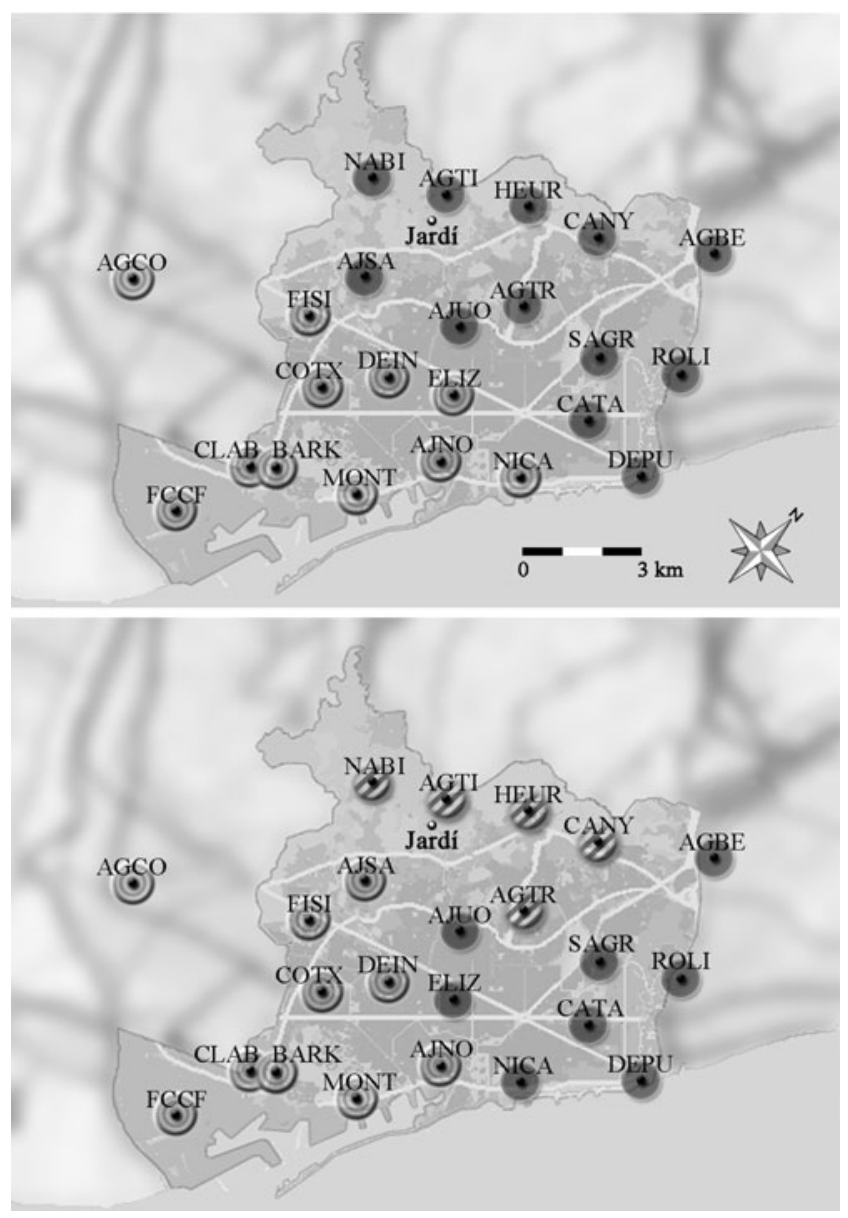

Fig. 2 Microscale rain gauge network supported by CLABSA and Jardí gauge at the Fabra Observatory of Barcelona. Principal component prevailing in every network station for a duration of $4 \mathrm{~h}$ (up) and 10 min (down). The upper representation shows a clear north-south distribution (first principal component in the north and second in the south), whereas the lower one reveals a substructure with a third component prevailing in the highest stations $(>150 \mathrm{~m})$
A further step in the analysis of the spatial correlation among the network is the determination of the minimum number of pluviometers needed to correctly characterize the regime of rainfall intensities over the urban area of Barcelona. The station-year method for regional analysis assumes the equivalence between records from $n$ pluviometers located in a climatologically homogeneous region during $d$ years and those registered by a single pluviometer in the same location with a longer data series of $n \times d$ years recorded (NRC 1988). This technique is useful to obtain a frequency distribution to correctly estimate the future probabilities of intense rain events to take place in the region where stations are located. This regional analysis assumes data from different stations to be statistically independent. However, it is usual to register in different stations a precipitation caused by the same meteorological event, so observations from different stations at the same time could not be independent and had to be related with an increasing correlation according to the proximity between stations. If this correlation is not considered, to add records from different pluviometers as a longer record from a single one could result in a overestimation of the return periods of the extreme precipitation events, even though the eventually inclusion of more extreme values could partially compensate this effect. To take into account, the spatial dependency effect between stations, an equivalent number of independent stations $n_{\mathrm{eq}}$ depending on the correlation between stations can be calculated (Nandakumar et al. 2000), and the number of years $n \times$ $d$ be reduced to a lower effective number $n_{\mathrm{eq}} \times \mathrm{d}$. The effective number of independent stations equivalent to the CLABSA network $n_{\text {eq }}$ has been estimated using the expression [1], derived from a method developed to estimate the spatial degrees of freedom (dof) of atmospheric flows, (Fraedrich et al. 1995; Bretherton et al. 1999). This statistical method compares the variance of the theoretical standardized chi-squared distribution with the sum of the squared eigenvalues of a spatial correlation matrix.

$n_{e q}=\frac{n^{2}}{\sum_{i j} \rho_{i j}^{2}}$

In Eq. (1), $n$ is the number of pluviometers, and $\rho_{\mathrm{ij}}$ is the Pearson's correlation coefficient between stations $i$ and $j$. This estimator was formulated assuming data to be normally distributed, serially independent, and to constitute a large sample. The network dataset can be considered a large sample of independent observations, but it is not normally distributed as in many geophysical applications. Despite of this, Bretherton et al. (1999) found that the estimator [1] is a good indicator of the number of dominant modes in the system for nonnormally observations. When the number of observations of a field is not large enough, the replacement of the ensemble average by the arithmetic average of the 
finite observations may result in errors in the eigenvalue calculation. Using North et al.'s (1982) rule of thumb for the typical error in eigenvalues of a correlation matrix determined from a limited set to observations, Wang and Sheng (1999) derived a formula [2] for the perturbation of the degrees of freedom (dof) useful to estimate the error of the $n_{\text {eq }}$ :

$\Delta n_{e q}=2 \sqrt{2 / M} n_{e q}$

where $M$ is the number of independent rainfall events. Figure 3 shows the $n_{\text {eq }}$ values obtained using [1] for every one of the durations considered, together with their lower and upper bounds estimated using [2]. According to these values, the CLABSA network constituted by 23 correlated pluviometers has resulted equivalent to 2 or 3 independent pluviometers for durations from $10 \mathrm{~min}$ to $4 \mathrm{~h}$ and less of 2 for longer durations, consistently with the principal component analysis results.

The recurrence of intense rainfall events recorded in Barcelona is currently estimated using the point rainfall IDF curves obtained by Casas et al. (2004) from the Jardí gauge records (Vilar and Burgueño 1995) of the Fabra Observatory of Barcelona (Fig. 2). To correctly estimate the recurrence of these events in the whole area, a peakover-threshold frequency analysis has been done. Extreme storms recorded by the network in the period 1994-2009 have been selected. The criterion of selection has been to show precipitation amounts overcoming the 1-year return period according to the point rainfall IDF curves for any of the considered durations from $10 \mathrm{~min}$ and $24 \mathrm{~h}$ at any of the network stations. The selected rainfall events are serially independent. The ratio $N / d$ of $N$ selected events in $d$ years for every duration would be expected to be of approximately

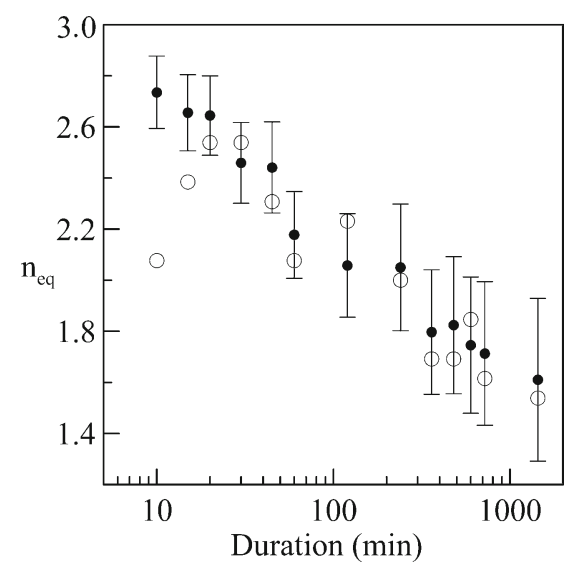

Fig. 3 Number of independent stations $n_{\text {eq }}$ (black-filled circles) equivalent to the urban network in function of the rainfall duration, in comparison with the ratio N/d (white-filled circles), denoting the number of observed rainfall events with a return period greater than 1 year $(N)$, divided by the number of years in the observed record $(d)$. Error bars indicate the lower and upper bounds estimated for $n_{\mathrm{eq}}$
1 if data would have been recorded by a single pluviometer. Since data have been registered by a network, this ratio results higher than 1 . As expected, storms registered by the network show an effective return period smaller than the return period observed when the same storms are registered by a single pluviometer, as the Jardí gauge. $N / d$ and $n_{\mathrm{eq}}$ values have resulted very similar for almost all durations (Fig. 3). The equivalent number of stations $n_{\text {eq }}$ almost fits with the number of storms with return period longer than 1 year recorded by the network in a year for durations longer than $20 \mathrm{~min}$. These results can be interpreted as follows: the effective return periods of storms registered by the network have decreased by a factor $1 / n_{\text {eq }}$ compared to the return periods observed by using the Jardí gauge. Values of $N / d$ and $n_{\text {eq }}$ fit worse for the shortest durations 10 and $15 \mathrm{~min}$, probably because at this small scale some of the storm cells producing intense precipitation are smaller than the network area and have not been properly registered by the network during the period of study.

\section{Spatial analysis of rainfall intensity in Barcelona}

In order to calculate areal rainfall amounts from the rainfall data recorded by the urban network, an objective spatial analysis of the rainfall intensity in Barcelona has been done. Using an interpolation method, precipitation fields over a regular grid with a spatial resolution of $300 \times 300 \mathrm{~m}$ over the urban area of Barcelona have been generated. Interpolation has been made for all the rainfall events which have been registered by at least eight pluviometers since 1994 to 2009, for durations from $10 \mathrm{~min}$ to $24 \mathrm{~h}$. The interpolation method consists of the recurrent application of Eq. (3), being $X^{a(k+1)}$ the precipitation value obtained from analysis in grid points for the iteration step $k+1$ and $X^{a(k)}$ the calculated one in the former step $k$. The precipitation value at each grid point is modified in every step based on the observations registered by $\mathrm{n}$ pluviometers. Differences between the precipitation data registered by the $\mathrm{j}$ pluviometer $\left(X_{j}^{o}\right)$ and the analyzed value $X_{j}^{a(k)}$ obtained in the particular grid point where this $\mathrm{j}$ pluviometer is located are then considered in every step, as well as a weighting function $w_{\mathrm{j}}$ which depends on how far the observation is from the grid point.

$X^{a(k+1)}=X^{a(k)}+\sum_{1}^{n} w_{j}\left(X_{j}^{0}-X_{j}^{a(k)}\right)$

The Barnes interpolation scheme (Barnes 1994; Koch et al. 1983), largely used for meteorological analysis, uses a weighting function $w_{\mathrm{j}}$ defined as the Gaussian expression [4], where $d_{\mathrm{j}}$ is the distance between the $\mathrm{j}$ pluviometer and the grid point, and $L$ is a shape parameter determining the 
influence of every pluviometer, depending on the distance from the grid point. This parameter has to be selected according to the characteristics of the network and can vary for each iteration step.

$w_{j}=\exp \left(-\frac{d_{j}^{2}}{2 L^{2}}\right)$

The analysis corresponding to the first step of the iterative process, $X^{a(0)}$, can be established by different procedures (Casas et al. 2007). In this case, a weighted average of data registered by each rain gauge has been calculated for every grid point using [5]. In order to take into account the most part of the network in this first step, a value of $L=10 \mathrm{~km}$ has been considered for the weighting function $w_{\mathrm{j}}$ defined by [4].

$X^{a(0)}=\frac{\sum_{1}^{n} w_{j} X_{j}^{0}}{\sum_{1}^{n} w_{j}}$

The shape parameter $L$ is gradually reduced with each iteration step until getting to the mean distance between neighboring pluviometers, which is $1.8 \mathrm{~km}$ in the urban network of Barcelona. This distance determines the maximum detail that can be established in the objective analysis of the network. Barnes (1973) proposed for the spacing grid a lower limit of one third of the mean distance, approximately $600 \mathrm{~m}$ in our case. After testing different spacing grids, a maximum resolution of $300 \mathrm{~m}$ has been selected since the structures detected with this resolution are compatible with the intensity data provided by the pluviometers of the employed network. Figure 4 shows some of the precipitation fields obtained using the described methodology.

A cross-validation technique has been used to test the goodness of the interpolation method. This technique provides an error value associated to the deviation between the calculated and the real values in the pluviometric stations using Eq. (6).

$\sigma=\left(\frac{1}{n} \sum_{1}^{n}\left(X_{j}^{0}-X_{j}^{\prime a(k)}\right)^{2}\right)^{\frac{1}{2}}$

$X_{j}^{\prime a(k)}$ is the precipitation estimated by interpolation in the grid point where pluviometer $\mathrm{j}$ is located, using $n-1$ values excluding $\mathrm{j}$. A coefficient of variation $\mathrm{CV}$ useful to compare errors between the different interpolations can be defined by [7]:

$C V=\frac{\sigma}{\frac{1}{n} \sum_{1}^{n} X_{j}^{0}}$

This evaluation technique has been applied to 1,546 interpolation fields corresponding to the 10-min interval of maximum intensity for every rainfall event within the period 1994-2009. Figure 5 shows the variation of CV with respect to the rainfall area represented by the number of pluviometers registering precipitation. Figure 6 shows the dependency of $\mathrm{CV}$ on duration when the whole network has registered rainfall. In particular for events with a return period higher than 5 years, the mean value of $\mathrm{CV}$ varies between 0.7 and 2 for a duration of $10 \mathrm{~min}$ and between 0.2 and 0.9 for $24 \mathrm{~h}$. Dirks et al. (1998) found similar values for longer durations using traditional interpolation methods as kriging, Thiessen, or inverse distance, whereas Enjamio et al. (2005) found values between 0.4 and 0.7 analyzing four rainfall events using an interpolation algorithm based on biharmonic splines. We can conclude that the Barnes interpolation method reproduces correctly the actual rainfall spatial variations, giving better results the more extensive the rainfall is and a longer duration is taken into consideration.

\section{Areal reduction factors of the metropolitan area of Barcelona}

The characteristic areal reduction factors (ARF) of the metropolitan area of Barcelona have been estimated using a "stormcentered" approach (Omolayo 1993; Svensson and Jones 2010). In the usual "storm-centered" methodology the ARF is calculated as the areal storm rainfall enclosed by a selected isohyet (being the rainfall everywhere in the enclosure at least as large as the value of the isohyet) divided by the maximum point rainfall at the storm center. In this work, the areal rainfall depths have been calculated from the high-resolution precipitation fields obtained in Section 3 using the interpolation method of Barnes with Gaussian weights. Instead of isohyets, circular areas around the point where the maximum of the interpolation is located have been considered for every storm. Areal precipitation expressed as the mean precipitation in every grid point inside the considered area, has been calculated for different distances from the central point. This procedure has been applied to the extreme storms (selected in Section 2) showing precipitation amounts overcoming the 1year return period for any of the considered durations from $10 \mathrm{~min}$ and $24 \mathrm{~h}$ at any of the network stations in the period 1994-2009. The obtained ARF values have been averaged for every distance (radius) considered. Figure 7 shows these mean ARF values for several durations and every distance. It has been found that ARF values generally increase with duration, especially for durations shorter than $12 \mathrm{~h}$, according to the fact that meteorological situations producing the highest precipitations over our territory correspond to mesoscale events with durations between 2 and $9 \mathrm{~h}$ (Casas et al. 2011). ARF values have shown very similar results for 12 and $24 \mathrm{~h}$ since rainfall events that give maximum precipitation for these durations, usually produced by synoptic systems, affect to regions much 
Fig. 4 Precipitation fields obtained by interpolation for July 15, 2001. a Rainfall amount $(\mathrm{mm})$ for different integration time values between 3:00 and 4:00 UTC. b Intensity $(\mathrm{mm} / \mathrm{min})$ for an integration time of $1 \mathrm{~min}$, between $3: 45$ and 3:55 UTC
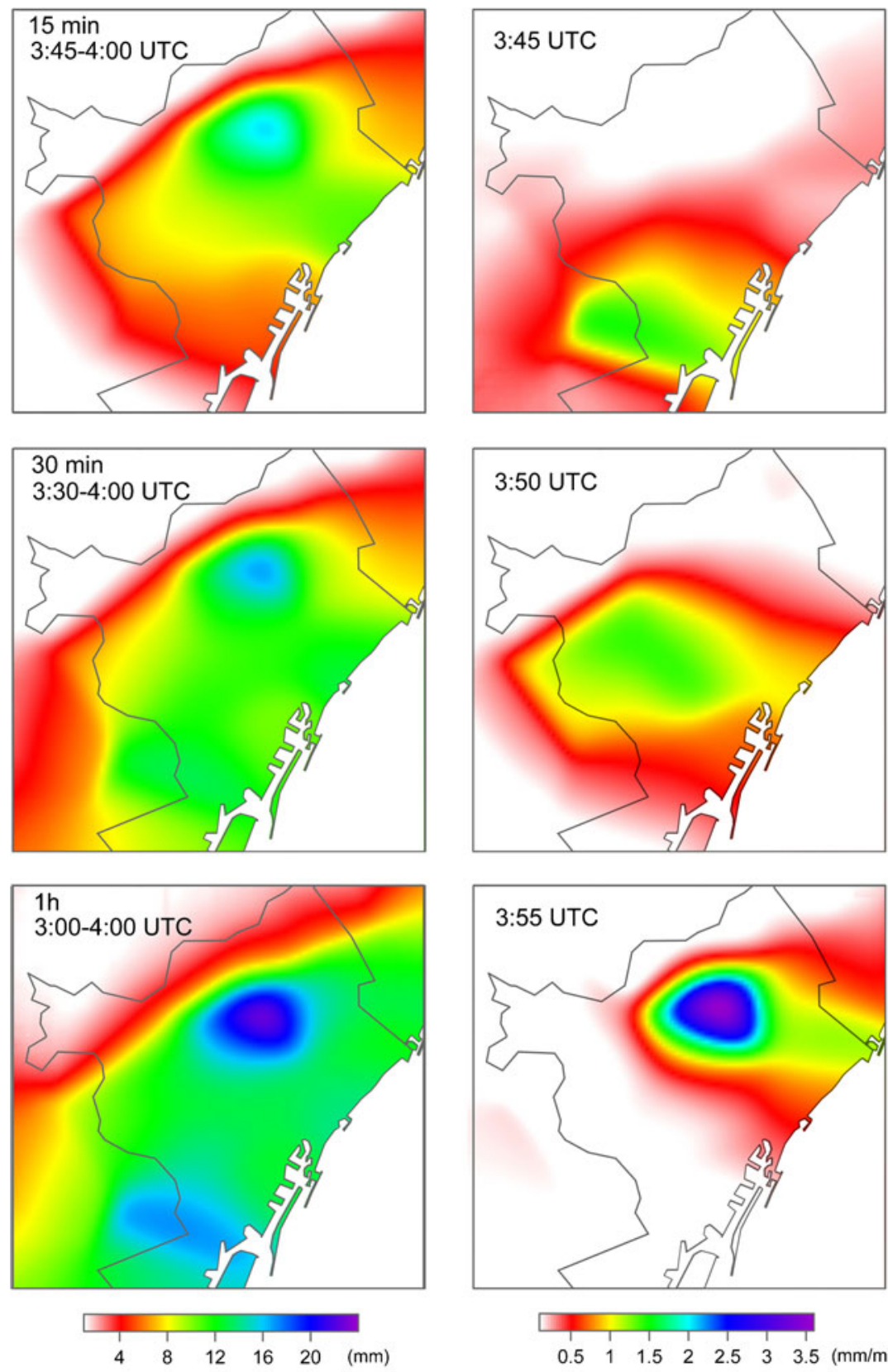

a

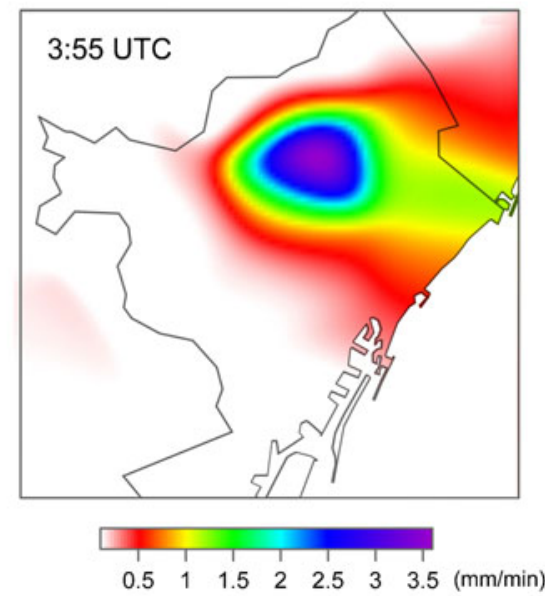

b larger than the urban network area. Thus, rainwater collected by the different network pluviometers is usually quite uniform.

ARF values are useful to estimate the probability of a storm to take place in a certain area (Vaes 2007). Thus, the return period of a rainfall event obtained using the point rainfall IDF relationships constructed from records of a single pluviometer can be recalculated using the ARF values to estimate the recurrence of this event in the area of study. In our case, a distance of $10 \mathrm{~km}$ from the point of maximum rainfall has to be considered to contemplate the whole urban area of Barcelona. For instance, if ARF is 0.58 for a duration of $24 \mathrm{~h}$ and a distance of $10 \mathrm{~km}$, a rainfall event with a point return period of 1 year is expected to take place with a recurrence of 0.58 years in the network. Figure 8 shows the general concordance between the ARF for $10 \mathrm{~km}$ and the inverse of the equivalent number of independent stations $1 / n_{\mathrm{eq}}$ of the urban network of Barcelona found in Section 2.

\section{Conclusions}

The mean value of the correlation coefficient of Pearson's among the records of the 23 pluviometers of the urban 


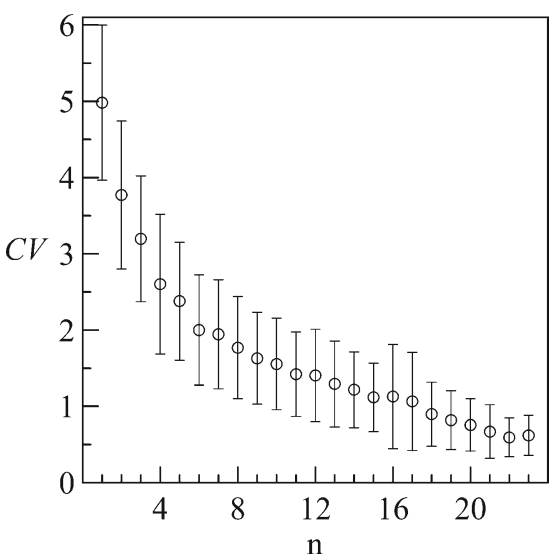

Fig. 5 Mean of the coefficient of variation CV (white-filled circles) versus the number $n$ of pluviometers registering precipitation for a duration of $10 \mathrm{~min}$. Error bars stand for one standard deviation

network of Barcelona in the period 1994-2009 has been found higher than 0.7 for durations longer than $6 \mathrm{~h}$. Applying the principal component analysis to this records, it has been found out that for events shorter than $4 \mathrm{~h}$, the first two principal components account for approximately the $70 \%$ of the total variance of the data and the $76 \%$ if a third component is added, whereas for durations longer than $4 \mathrm{~h}$, the first two principal components account for the $86 \%$ of the variance. The spatial representation of the prevailing principal component in every station shows two or three pluviometric zones over the urban area of Barcelona, depending on the rain duration. For mesoscale durations, a clear north-south rainfall distribution over the urban area has been found. For lower durations, the principal component analysis shows a third zone corresponding to the highest stations of Barcelona.

The estimation of the number $n_{\text {eq }}$ of independent stations equivalent to the network has resulted between 2 and 3 for rainfall between $10 \mathrm{~min}$ and $4 \mathrm{~h}$, and less than 2 for longer

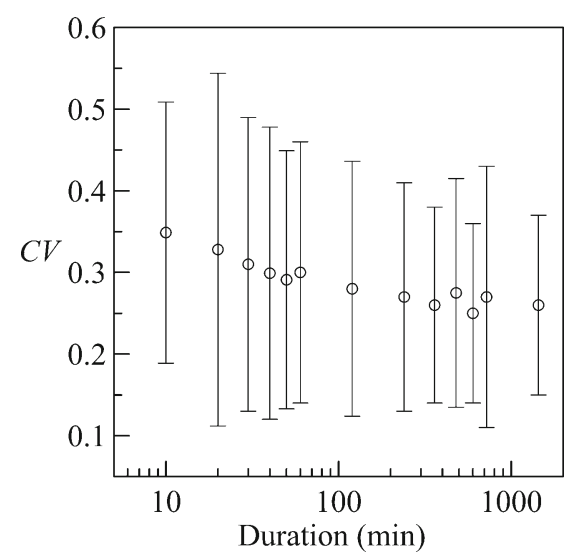

Fig. 6 Mean of the coefficient of variation CV (white-filled circles) versus rain duration for the rainfall events registered by the 23 pluviometers of the urban network. Error bars stand for one standard deviation

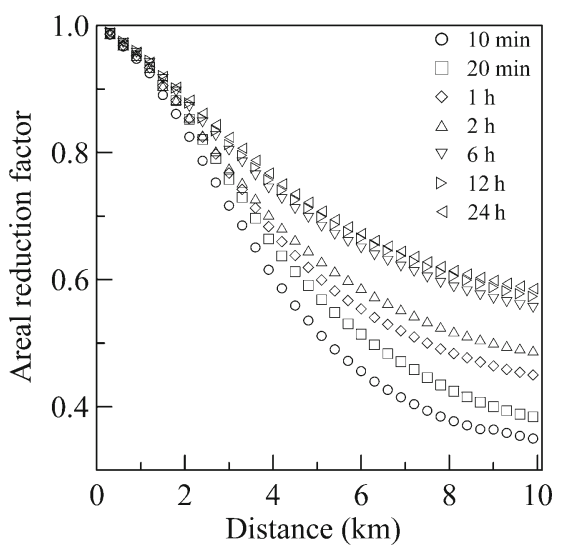

Fig. 7 ARF values calculated using the "storm-centered" approach for several durations

durations. A large agreement between the number of storms with return period longer than 1 year recorded by the network in a year, and the number $n_{\text {eq }}$ of independent stations has been obtained for durations longer than $20 \mathrm{~min}$. An interpretation of this result is that the observed return period for a storm registered by the network approximately decreases by a factor of $1 / n_{\mathrm{eq}}$ compared to the return period assigned by the point rainfall IDF relationships.

The Barnes interpolation method employed to obtain high-resolution precipitation fields from data provided by the network reproduces correctly the actual rainfall spatial variations, showing better results the more extensive the rainfall is and a longer duration is considered. The mean value of a coefficient of variation CV measuring the goodness of the Barnes interpolation method has resulted between 0.7 and 2 for $10 \mathrm{~min}$ and between 0.2 and 0.9 for $24 \mathrm{~h}$. These CV values are similar to those found by other authors for longer durations and traditional interpolation methods as kriging or spline functions. These highresolution precipitation fields have been used to calculate

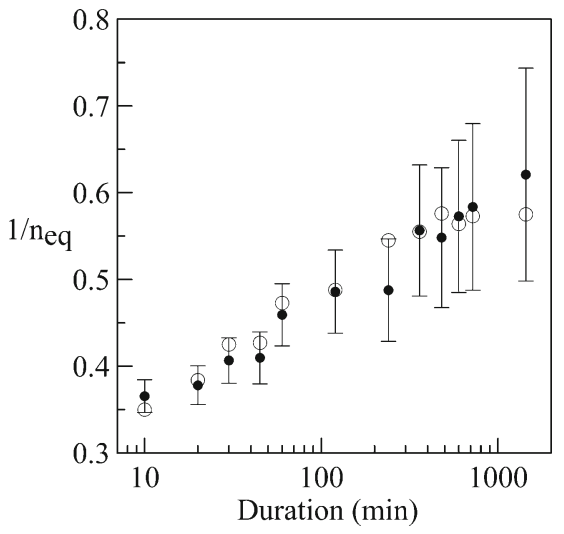

Fig. 8 Comparison between the inverse of the equivalent number of independent stations $1 / n_{\mathrm{eq}}$ (black-filled circles) for the urban network of Barcelona and the ARF for the network representative length of $10 \mathrm{~km}$ (white-filled circles). Error bars indicate the lower and upper bounds estimated for $1 / n_{\mathrm{eq}}$ 
areal rainfall depths and, using a "storm-centered" approach, the ARF values for the urban area of Barcelona. These ARF values have been found to increase with duration, especially for durations shorter than $12 \mathrm{~h}$.

A great concordance between the ARF values for $10 \mathrm{~km}$ (a representative length of the urban area) and the inverse of the equivalent number of independent stations of the network $1 / n_{\text {eq }}$ has been observed. Since this factor $1 / n_{\text {eq }}$ has also been found between the observed recurrences of a storm registered by a network and by a single gauge, a relationship can be established between the ARFs corresponding to a network area and the observed recurrence of a storm recorded by this network. Thus, the probability of a rainfall event taking place in a region can be estimated from the return period of this event based on the point rainfall IDF curves by multiplying it by the ARF corresponding to the area of this region.

Acknowledgments This work was supported by the Ministry of Science and Innovation of Spain under Grant CGL2007-65891-C0503. The authors are also grateful to Clavegueram de Barcelona S.A. (CLABSA) for providing the rain data used in this study.

\section{References}

Barnes SL (1973) Mesoscale objective analysis using weighted timeseries observations. NOAA Tech. Memo. ERL NSSL-62, U.S. Dept. of Commerce, 60

Barnes SL (1994) Applications of the Barnes objective analysis scheme. Part I: effects of undersampling, wave position, and station randomness. J Atmos Ocean Technol 11:1433-1448

Bretherton C, Widmann M, Dymnikov V, Wallace J, Bladé I (1999) The effective number of spatial degrees of freedom of a timevarying field. J Clim 12:1990-2009

Casas MC, Codina B, Redaño A, Lorente J (2004) A methodology to classify extreme rainfall events in the western Mediterranean area. Theor Appl Climatol 77:139-150

Casas MC, Herrero M, Ninyerola M, Pons X, Rodríguez R, Rius A, Redaño A (2007) Analysis and objective mapping of extreme daily rainfall in Catalonia. Int J Climatol 27:399-409

Casas MC, Rodríguez R, Redaño A (2010) Analysis of extreme rainfall in Barcelona using a microscale rain gauge network. Meteorol Appl $17: 117-123$

Casas MC, Rodríguez R, Prohom M, Gázquez A, Redaño A (2011) Estimation of the probable maximum precipitation in Barcelona (Spain). Int J Climatol 31:1322-1327
Dirks KN, Hay JE, Stow CD, Harris D (1998) High-resolution studies of rainfall on Norfolk Island. Part II: interpolation of rainfall data. J Hydrol 208:187-193

Enjamio C, Vilar E, Redaño A, Fontán FP, Ndzi D (2005) Experimental analysis of microscale rain cells and their dynamic evolution. Radio Science 40:RS3015. doi:10.1029/1004RS003119

Fraedrich K, Ziehmann C, Sielmann F (1995) Estimates of spatial degrees of freedom. J Clim 8:361-369

Hosking JRM, Wallis JR (1997) Regional frequency analysis: an approach based on L-moments. Cambridge University Press, Cambridge, UK, pp 224

Koch SE, desJardins M, Kocin PJ (1983) An interactive Barnes objective map analysis scheme for use with satellite and conventional data. J Clim Appl Meteorol 22:1487-1503

Lanza L, Leroy M, Alexandropolos C, Stagi L, Wauben W (2006) WMO laboratory intercomparison of rainfall intensity gauges. Instruments and observing methods, Report No. 84. WMO/TDNo.1304

Lorente J, Redaño A (1990) Rainfall rate distribution in a local scale: the case of Barcelona City. Theor Appl Climatol 41:23-32

Mikkelsen PS, Madsen H, Arnbjerg-Nielsen K, Rosbjerg D, Harremoës P (2005) Selection of regional historical rainfall time series as input to urban drainage simulations at ungauged locations. Atmos Res 77:4-17

Nandakumar N, Weinmann PE, Mein RG, Nathan RJ (2000) Estimation of spatial dependence for the CRCFORGE Method. Hydro 2000: interactive hydrology; Proceedings. Barton, A.C.T.: Institution of Engineers, Australia, 2000: 553-557. <http://search.informit. com.au/documentSummary; $\mathrm{dn}=295216092038807$;res=IELENG> ISBN: 0957824114

National Research Council (1988) Estimating probabilities of extreme floods. Methods and recommended research. National Academy Press, Washington, D.C

Niemczynowicz J, Bengtsson L (1996) What practitioners need f rom theoreticians? Atmos Res 42:5-17

North G, Bell TR, Cahalan R, Moeng F (1982) Sampling errors in estimation of empirical orthogonal functions. Mon Weather Rev 110:699-706

Omolayo AS (1993) On the transposition of areal reduction factors for rainfall frequency estimation. J Hydrol 145(1-2):191-205

Shah SMS, O'Connell PE, Hosking JRM (1996) Modelling the effects of spatial variability in rainfall on catchment response. 1. Formulation and calibration of a stochastic rainfall field model. J Hydrol $175: 67-88$

Svensson C, Jones DA (2010) Review of methods for deriving areal reduction factors. J Flood Risk Management 3:232-245

Vaes G (2007) The spatial relevance of extreme rainfall events. 6th International Conference on sustainable techniques and strategies for urban water management NOVATECH 2007. Lyon, France

Vilar E, Burgueño A (1995) Statistical properties of 49 years of rainfall rate events. Theor Appl Climatol 50:213-225

Wang X, Sheng SS (1999) Estimation of spatial degrees of freedom of a climate field. J Clim 12:1280-1291 